\title{
Editorial
}

\section{Fiebre amarilla}

La fiebre amarilla (FA) ha jugado un papel histórico en la salud del área latinoamericana. La reunión en Washington, del 2 de diciembre de 1902, de 11 países del área, entre ellos Costa Rica representada por el Dr. Juan Ulloa, durante la Primera Convención Sanitaria Internacional de las Repúblicas Americanas, para discutir sobre la epidemia de la fiebre amarilla que en aquel momento estaba causando gran cantidad de muertes, dio origen a lo que posteriormente se conocería como la Organización Panamericana de la Salud.

En la actualidad se estima que ocurren 200,000 casos y 30,000 muertes al año. La infección es endémica en las regiones tropicales de África y Sur América, cerca de 90\% de los casos y muertes por FA, ocurren en África ${ }^{1}$. Recientemente ha habido un aumento en la densidad y distribución del mosquito a nivel urbano en muchas regiones del mundo, lo que aunado a la gran cantidad de vuelos diarios y al creciente interés por el ecoturismo, ha ocasionado que el riesgo de introducir y diseminar la FA, en América Central, América del Norte haya aumentado 2.

La fatalidad de los casos, es alta, del $30 \%$ o más, no hay tratamiento específico, lo que hace del manejo de estos pacientes extremadamente problemático ${ }^{3}$.

El resurgimiento de la FA en los últimos 30 años, no ha sido tan dramático como el de dengue y dengue hemorrágico. Sin embargo la actividad epidémica en África y América, es preocupante; los brotes en la mayoría de estos lugares han sido limitados y asociados a ciclos selváticos. En América, los brotes han ocurrido en Perú, Ecuador, Venezuela, Bolivia y Brasil ${ }^{4-7}$. Muchos de ellos ocurrieron en áreas cercanas a zonas urbanas, donde el Ae. aegypti estaba presente. En al menos uno de los brotes en Santa Cruz, Bolivia la transmisión urbana fue bien documentada ${ }^{5}$.

La FA es una zoonosis que no puede ser erradicada, ya que los reservorios animales no pueden ser eliminados, aún así la vacunación rutinaria en áreas de endemicidad puede reducir el espectro de la enfermedad.

El artículo de Iglesias-Rosales y colaboradores, adquiere actual importancia ante el creciente aumento de casos de dengue en nuestro país, y al ser el Aedes aegypti el vector de ambas infecciones, la alerta ante eventuales casos de fiebre amarilla debe ser mantenida. El cuerpo médico requiere estar capacitado y calificado para establecer el diagnóstico diferencial, ya que la aparición de un caso, implicaría el inicio de campañas masivas de vacunación para evitar una epidemia en el territorio nacional. Solo mediante la vigilancia epidemiológica y el diagnóstico temprano de casos podremos evitar el resurgimiento de esta infección en nuestro país.

Dra. María L. Ávila-Agüero.

Pediatra Infectóloga Jefe del Servicio de Infectología del Hospital Nacional de Niños y usar el correo: maluvi@racsa.co.cr

ISSN 0001-6002/2005/47/3/108 Acta Médica Costarricense, $(2005$ Colegio de Médicos y Cirujanos

\section{Referencias}

1. Tomori O. Yellow fever: the recurring plague. Crit Rev Clin Lab Sci. 2004;41:391-427.

2. Gubler D.J.. The changing epidemiology of yellow fever and dengue, 1900 to 2003: full circle? Comp. Immun. Microbiol. Infect. Dis. 2004; 27:319-30

3. Gubler DJ. Dengue and dengue hemorrhagic fever. Clin Microbiol Rev 1998; 11:480-96.

4. PAHO. http://www.paho.org/English/AD/FCH/IM/YellowFever.htm

5. Van der Stuyft P, Gianella A, Pirard M, Cespedes J, Lora J, Peredo C, Pelegrino JL, Vorndam V, Boelaert M. Urbanization of yellow fever in Santa Cruz, Bolivia. Lancet 1999;353:1558-62.

6. Massad E, Bezerra Coutinho FA, Nascimento Burattini MN, Fernández Lopez L. The risk of yellow fever in a dengue-infested area. Trans R Soc Trop Med Hyg 2001;95:370-4.

7. Bryant J, Wang H, Cabezas C, Ramirez G, Watts D, Russell K, Barrett A. Enzootic transmission of yellow fever virus in Peru. EID 2003;9:926-33. 